\title{
Cost-effectiveness analyses comparing cemented, cementless, hybrid and reverse hybrid fixation in total hip arthroplasty: a systematic overview and critical appraisal of the current evidence
}

Citation for published version (APA):

Veldman, H. D., de Bot, R. T. A. L., Heyligers, I. C., Boymans, T. A. E. J., \& Hiligsmann, M. (2021). Costeffectiveness analyses comparing cemented, cementless, hybrid and reverse hybrid fixation in total hip arthroplasty: a systematic overview and critical appraisal of the current evidence. Expert Review of Pharmacoeconomics \& Outcomes Research, 21(4), 579-593.

https://doi.org/10.1080/14737167.2021.1878880

Document status and date:

Published: 04/07/2021

DOI:

$10.1080 / 14737167.2021 .1878880$

Document Version:

Publisher's PDF, also known as Version of record

Document license:

Taverne

Please check the document version of this publication:

- A submitted manuscript is the version of the article upon submission and before peer-review. There can be important differences between the submitted version and the official published version of record. People interested in the research are advised to contact the author for the final version of the publication, or visit the DOI to the publisher's website.

- The final author version and the galley proof are versions of the publication after peer review.

- The final published version features the final layout of the paper including the volume, issue and page numbers.

Link to publication

\footnotetext{
General rights rights.

- You may freely distribute the URL identifying the publication in the public portal. please follow below link for the End User Agreement:

www.umlib.nl/taverne-license

Take down policy

If you believe that this document breaches copyright please contact us at:

repository@maastrichtuniversity.nl

providing details and we will investigate your claim.
}

Copyright and moral rights for the publications made accessible in the public portal are retained by the authors and/or other copyright owners and it is a condition of accessing publications that users recognise and abide by the legal requirements associated with these

- Users may download and print one copy of any publication from the public portal for the purpose of private study or research.

- You may not further distribute the material or use it for any profit-making activity or commercial gain

If the publication is distributed under the terms of Article 25fa of the Dutch Copyright Act, indicated by the "Taverne" license above,

Download date: 26 Apr. 2023 


\title{
Cost-effectiveness analyses comparing cemented, cementless, hybrid and reverse hybrid fixation in total hip arthroplasty: a systematic overview and critical appraisal of the current evidence
}

\author{
H.D. Veldman (10) ${ }^{a, b}$, R.T.A.L. de Bot ${ }^{b, c}$, I.C. Heyligers ${ }^{a, d}$, T.A.E.J. Boymans ${ }^{c}$ and M. Hiligsmann $\mathbb{0}^{b}$ \\ aZuyderland Medical Center, Dept. Of Orthopaedic Surgery and Traumatology, Heerlen, The Netherlands; ${ }^{b}$ Care and Public Health Research \\ Institute (CAPHRI), Maastricht University, Dept. Of Health Services Research, Maastricht, The Netherlands; 'Maastricht University Medical Center, \\ dept. of Orthopaedics, Maastricht, The Netherlands; ${ }^{d}$ School of Health Professions Education (SHE), Maastricht University, Maastricht, The \\ Netherlands
}

ABSTRACT

Background: This study aims to present an overview and critical appraisal of all previous studies comparing costs and outcomes of the different modes of fixation in total hip arthroplasty (THA). A secondary aim is to provide conclusions regarding the most cost-effective mode of implant fixation per gender and age-specific population in THA, based on high quality studies.

Methods: A systematic search was conducted to identify cost-effectiveness analyses (CEAs) comparing different modes of implant fixation in THA. Analysis of results was done with solely CEAs that had a high methodological quality.

Results: A total of 12 relevant studies were identified and presented, of which 5 were considered to have the methodological rigor for inclusion in the analysis of results. These studies found that either cemented or hybrid fixation was the most cost-effective implant fixation mode for most age- and gender-specific subgroups.

Conclusion: Currently available well performed CEAs generally support the use of cemented and hybrid fixation for all age-groups relevant for THA and both genders. However, these findings were mainly based on a single database and depended on assumptions made in the studies' methodology. Issues discussed in this paper have to be considered and future work is needed.
ARTICLE HISTORY

Received 23 August 2020

Accepted 18 January 2021

\section{KEYWORDS}

total hip arthroplasty; implant fixation; costeffectiveness; cemented; cementless; hybrid; reverse hybrid

\section{Introduction}

Total hip arthroplasty (THA) achieves excellent long-term results and is among the most successful interventions in Orthopaedic surgery $[1,2]$. As a consequence, the utilization of THAs has increased worldwide in the past decades and is expected to continue to rise the upcoming years [3-7].

Fixation of components in THA can be obtained either by cemented or cementless fixation, or by a combination of both (i.e. hybrid [cemented stem and cementless cup] or reverse hybrid [cementless stem and cemented cup]). The preferred mode of fixation is still prone to debate. Compared to cementless fixation, the use of bone cement is associated with a higher cardiopulmonary risk [8] and an approximately 10 minute longer operative time due to the polymerization of the bone cement $[9,10]$. Additionally, bone cement is prone to cement aging and microfractures, which may result in longterm implant failure [11]. Cementless fixation on the other hand, is associated with a higher risk of revision and lower implant survival on short term, particularly in elderly patients [12-14]. Recent meta-analyses have suggested that the newer and more innovative cementless components might not have any additional benefits over contemporary cemented THAs [14-16].
The popularity of cementless fixation has increased in the past decades, which is represented by the trends of fixation methods used in arthroplasty registries [12,17-20]. In most countries, the majority of THAs is currently fixated without the use of bone cement [12,17-19,21-23], while high variability is seen between countries. In the USA for example, $96 \%$ of all THAs is fixated without the use of bone cement [18]. In the UK, cemented fixation of at least one component currently consists $57 \%$ of all THA procedures [24]. Comparable statistics were found for Norway [25], while in other Scandinavian countries cemented fixation of all components is the predominant mode of fixation $[20,23,26]$.

Due to increasing healthcare costs, orthopaedic surgeons are under pressure to provide optimal cost-effective care. Studies solely focussing on cost estimations have suggested that cementless fixation might be associated with higher costs compared to cemented fixation due to higher implant costs and lower overall short-term implant survival $[27,28]$. The question rises whether these extra costs are accompanied by superior long-term results in certain patient populations.

A high-quality cost-effectiveness analysis (CEA) in health economics enables researchers to gain insight in the combination of costs and outcomes in a standardized and methodological solid 
fashion. CEAs therefore may help to identify patient populations in which a certain mode of fixation is the most cost-effective, and thus may guide decision making. However, a good overview and critical appraisal of all currently available health economic evidence regarding component fixation in THA is still missing.

Therefore, the primary aim of this systematic review is to present an overview and critical appraisal of all previous studies comparing costs and outcomes of the different modes of fixation in THA. A secondary aim is to provide conclusions on the optimal mode of implant fixation per gender and agespecific population in THA based on high quality costeffectiveness analyses, and to put these conclusions into perspective.

\section{Material and methods}

The present study is structured according to the Preferred Reporting Items for Systematic Reviews and Meta-Analyses (PRISMA) statement [29]. Two reviewers (HV \& RdB) independently conducted a systematic search of Medline, EMBASE, the Web of Science, the Cochrance Central Register of Controlled Trials, and EconLit. The search consisted of a combination of terms related to the intervention (i.e. 'hip arthroplasty', 'total hip arthroplasty', 'THA', 'hip replacement', 'total hip replacement', 'THR', 'total hip prosthesis', 'THP', 'hip prosthesis' or 'hip implant'), to the fixation mode (i.e. 'cemented', 'cement', 'cementless', 'uncemented', 'fixation', 'hybrid', 'reverse hybrid' or 'implant fixation'), and to the type of study/outcome (i.e. 'cost-effectiveness', 'CEA', 'cost-utility', 'CUA', 'cost-benefit', 'CBA', 'economic evaluation', 'health technology assessment', 'HTA', 'health economics', 'cost analysis', 'costs', 'cost', 'economic', 'ICER' or 'ICUR'). For searching the database, the mentioned terms inside the parentheses were connected to each other with 'OR'. Subsequently, the (with 'OR' connected) terms on the intervention, the fixation mode, and the type of study/ outcome were connected to each other with 'AND'. This strategy was used for each of the five databases. Additionally, backward and forward reference searching was applied on the publications suitable for inclusion in order to identify additional eligible studies. The search was updated to include hits up until February 1st 2020. The compliance of each article with the inclusion criteria was independently assessed by the two reviewers. Any disagreements were solved by discussion and consultation of a third author $(\mathrm{MH})$.

Studies were considered eligible for inclusion if they compared the outcomes and associated costs of different modes of fixation in THA. Costs could be expressed in any monetary value. Outcomes could be expressed in any defined 'unit of health' (e.g. implant survival) or in 'Quality Adjusted Life Years' (QALYs). When comparing interventions in a methodologically sound fashion via a health economic cost-effectiveness or cost-utility analysis, the difference in costs is divided by the difference in outcome, which is called the incremental costeffectiveness ratio (ICER) or incremental cost-utility ratio (ICUR) respectively [30]. Based on the ICUR, four possible conclusions can be drawn: (i) the intervention treatment is dominated (i.e. the intervention treatment is more expensive and less effective), (ii) the intervention treatment dominates (i.e. the intervention treatment is cheaper and more effective), (iii) the intervention treatment is more effective and also more expensive; whether the intervention is advocated is then based on the willingness to pay, and (iv) the intervention treatment is less effective and cheaper; whether the new interventions is then advocated is based on the willingness to accept. Based on the willingness to pay threshold, gains in quality of life could also be converted to a monetary value in case of incremental net monetary benefit-analyses (INMB). Studies were included if they compared at least two different fixation modes, and if they were available as an original full text scientific article written in English. No other restrictions were made regarding the characteristics of studies, nor the publication date, in order to provide a complete overview of all studies on this topic.

All relevant data from the included articles were independently extracted by two reviewers (HV \& RdB). Data items of interest included study characteristics and the results of the individual studies. Assessment of the methodological quality of the identified economic evaluations was independently performed by two authors (HV \& RdB) with the use of the 'Quality of Health Economic Studies (QHES)' instrument $[31,32]$. The QHES is a validated instrument which is used to examine the quality of a CEA according to the health economic principles. The tool contains 16 carefully selected criteria that should be answered with 'yes' or 'no'. Each criterion has a certain amount of points allocated, and by adding up the points for the criteria answered 'yes', an overall quality score is acquired [31,32]. An economic evaluation of high quality scores $\geq 75$ points, 50 to 74 points is considered fair, and insufficiently performed studies score $<50$ points $[31,33]$. Any disagreements in the methodological assessment were solved by discussion and consultation of a third author (MH).

To answer the second aim, i.e. to define the optimal mode of implant fixation per gender and age-group from a costeffectiveness perspective, additional criteria were applied. The studies had to meet two criteria: (i) the QHES score should indicate a high quality (score $\geq 75$ ) and (ii) a sufficient time horizon had to be investigated ( $\geq 10$ years). These criteria were stated because studies with inferior methodological quality and unclear reporting negatively impact the solidness of derived conclusions. Additionally, studies with a short-term time horizon mainly focus on initial costs (e.g. implant and surgical procedure), while the real costs are made over a lifetime and are therefore much impacted by the implant's long-term effectiveness and survival rate. A 10-year period was chosen as the absolute minimum since a recently published extensive analysis on THA survival by Evans et al. concludes that an estimated $75 \%$ of all THAs last at least 15 to 20 years [34].

From the high-quality studies with sufficient follow-up, base case incremental results were derived or calculated. Depending on the reporting of the individual studies, the ICER, ICUR or INMB were reported and used for the interpretation of results. Interpretation of results was done by comparing the methodology, the input data and the reported results in the search of overall trends. Assessment of trends was performed on the conclusions based on data as published by individual studies. In order to ensure transparency and verifiability, no single reference year was chosen or conversion 
to a single currency had been performed. Since we did not aim to recalculate the evidence toward a single currency, a willingness to pay threshold was adopted for the three most commonly used currencies in CEAs. We adopted a willingness to pay threshold of 20,000 Euros $(€)$ or Sterling pounds ( $£$ ) per QALY, and 25,000 USD (\$) per QALY. Although no absolute societal consensus exists on the threshold of the willingness to pay, these are more or less comparable, frequently used and widely accepted thresholds for each of those currencies [35-38]. In case another currency was used in an included study, a comparable willingness to pay threshold will be applied.

\section{Results}

\subsection{Study selection}

The initial search yielded a total of 1,821 hits (Figure 1). Title and abstract screening resulted in 259 studies potentially describing THA and associated economics. After the removal of duplicates, a total of 141 full text articles of potential relevance were obtained and assessed. Subsequently, 13 relevant studies remained after the exclusion of 128 records. From the excluded records, most studies were excluded because they were not related to different implant fixation modes $(n=103)$. Other articles were excluded because they only focused on costs without the incorporation of treatment consequences $(n=14)$, or because the papers were no original scientific articles $(n=11)$. In depth analysis of the 13 relevant studies revealed that the data derived from one RCT was published in three different publications [39-41]. Data in these studies were identical, while the study of Rorabeck et al. was the most extensive description of this population [40]. Therefore, only this publication was included in our review [40]. Two studies performed by Pennington and colleagues $[42,43]$ used comparable methodologies, but performed different analyses. Therefore, these analyses were both included in the current report $[42,43]$. In addition to the 11 suitable studies identified with our search, one additional study was identified through backward reference searching of those studies [44]. Therefore, a total of 12 studies were included in this systematic review [40,42-52].

\subsection{Study characteristics}

An overview of the included studies, which were published between 1994 and 2020, is presented in Table 1. The comparisons differed between the included studies: one study solely

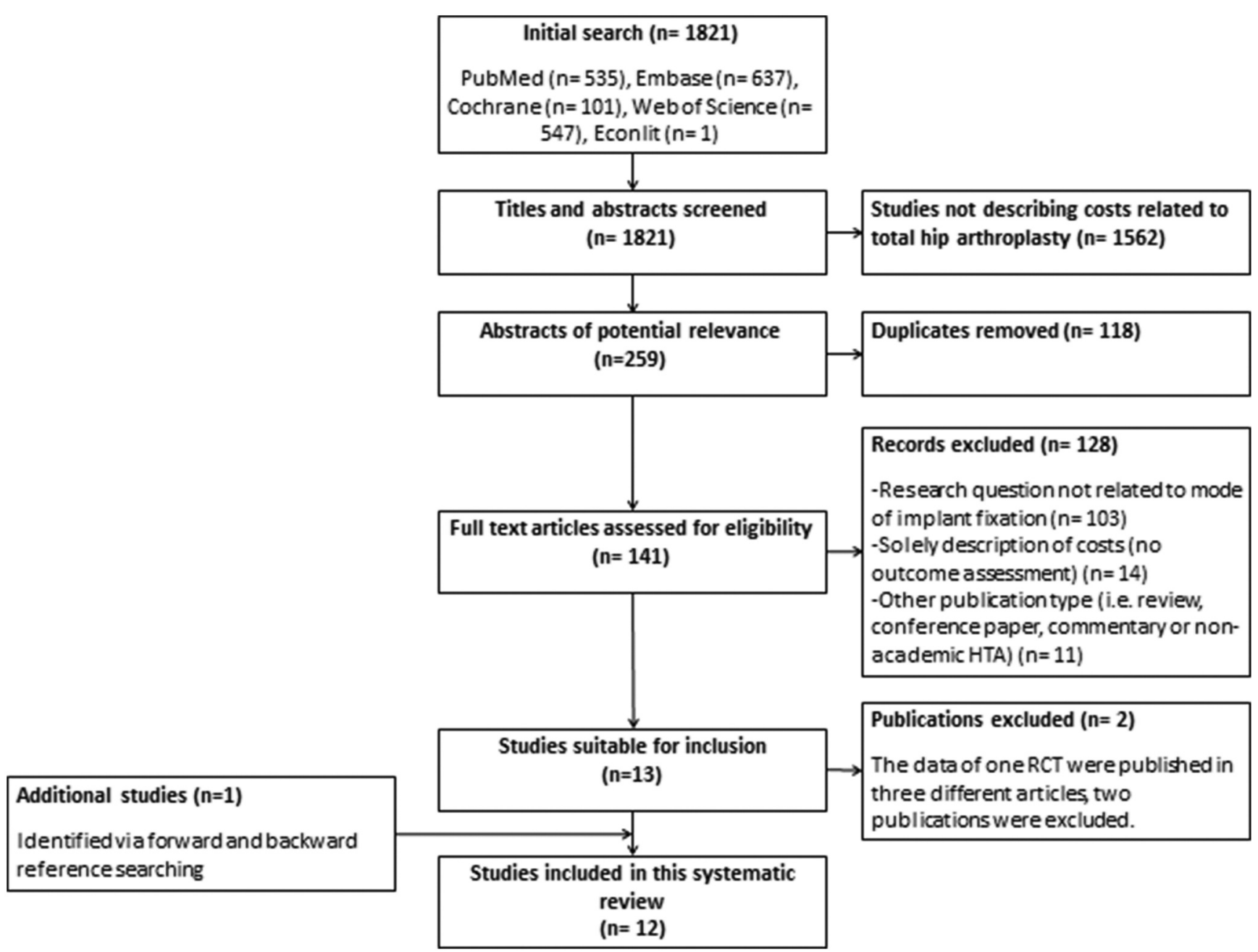

Figure 1. Flow chart of the selection of studies included in this systematic review. 


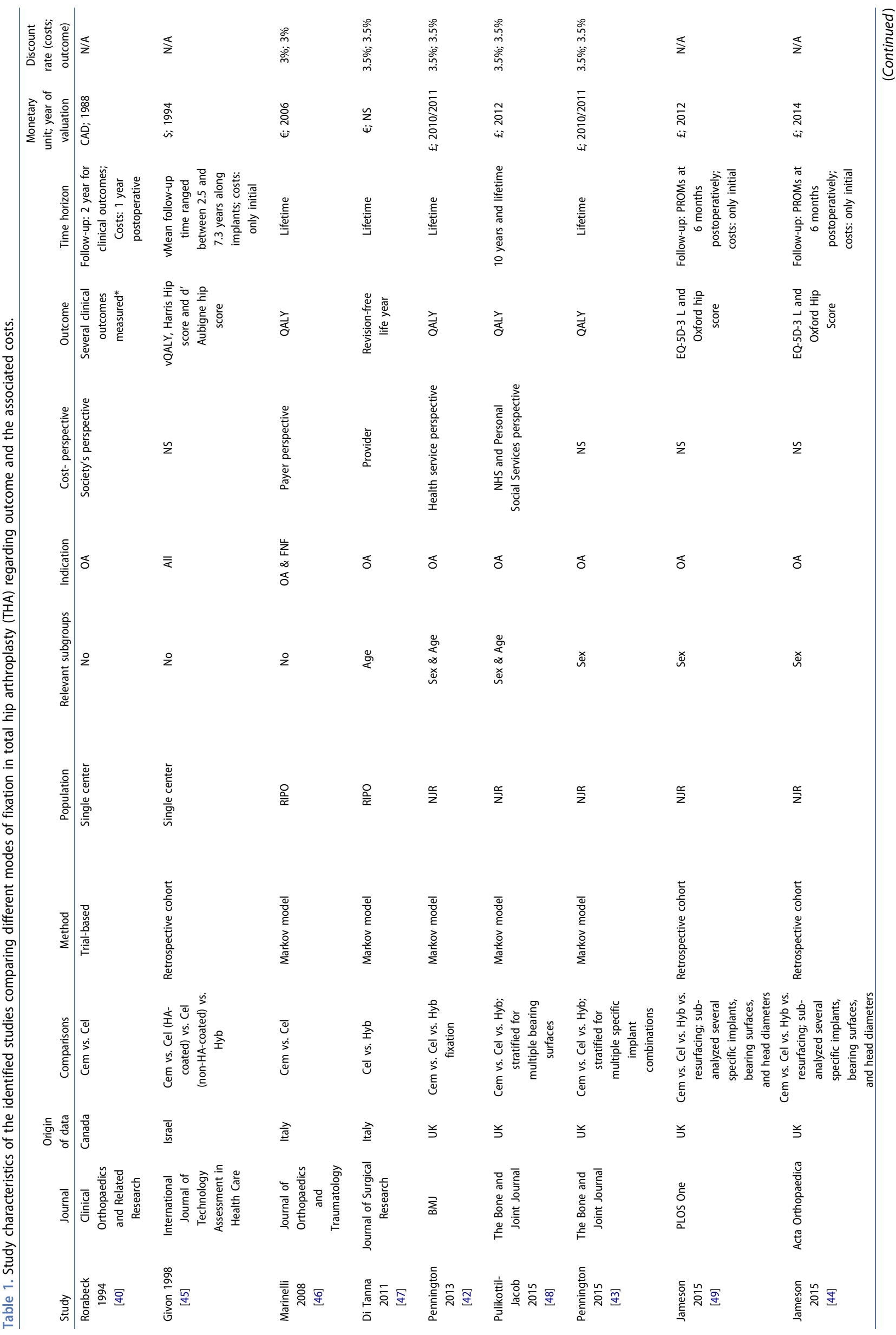




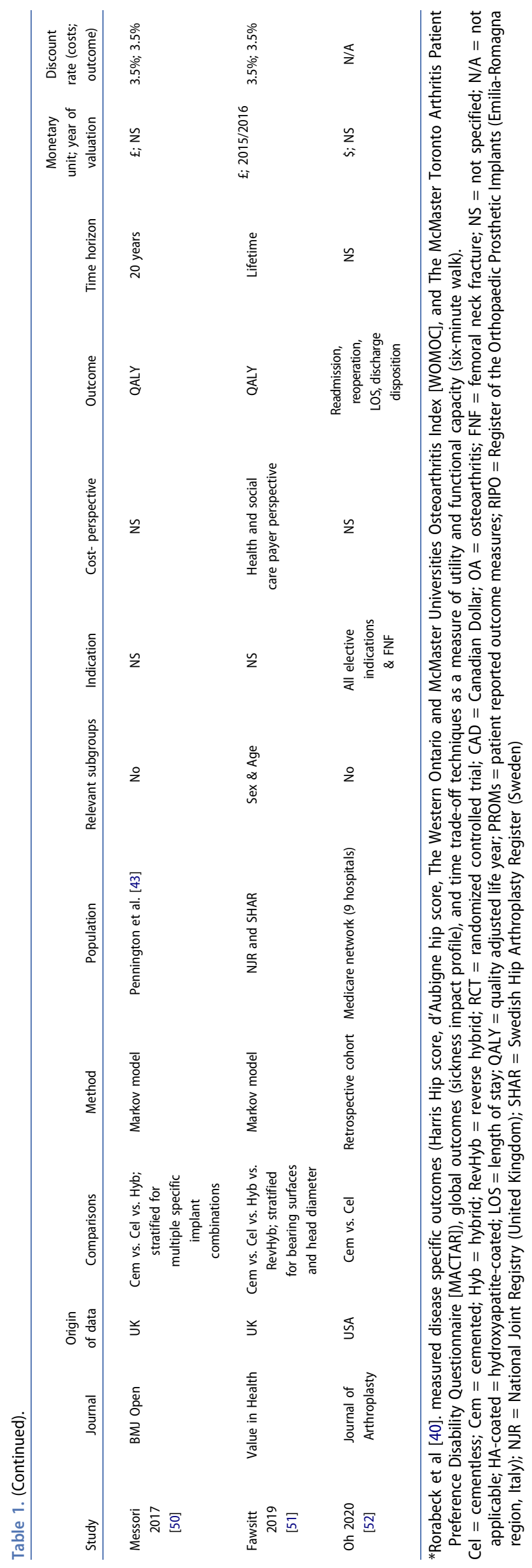




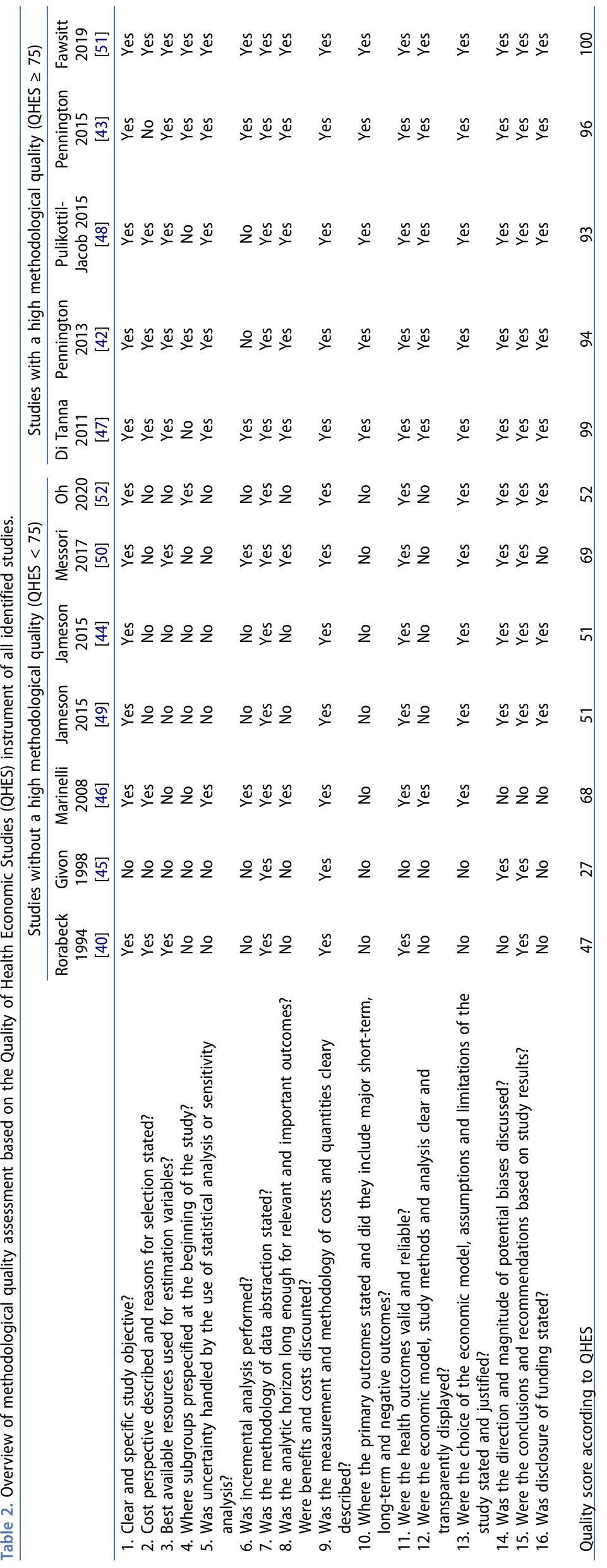




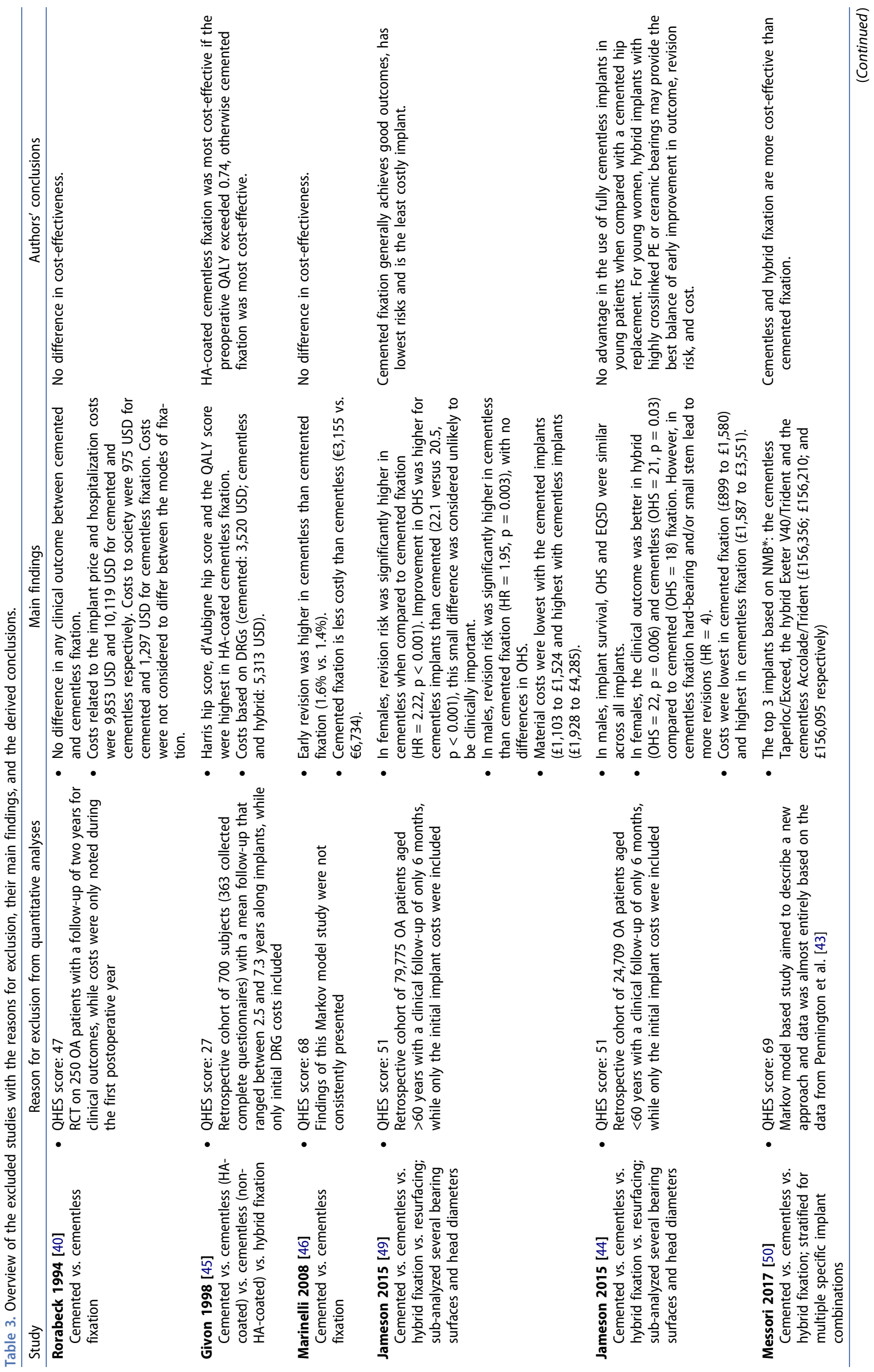




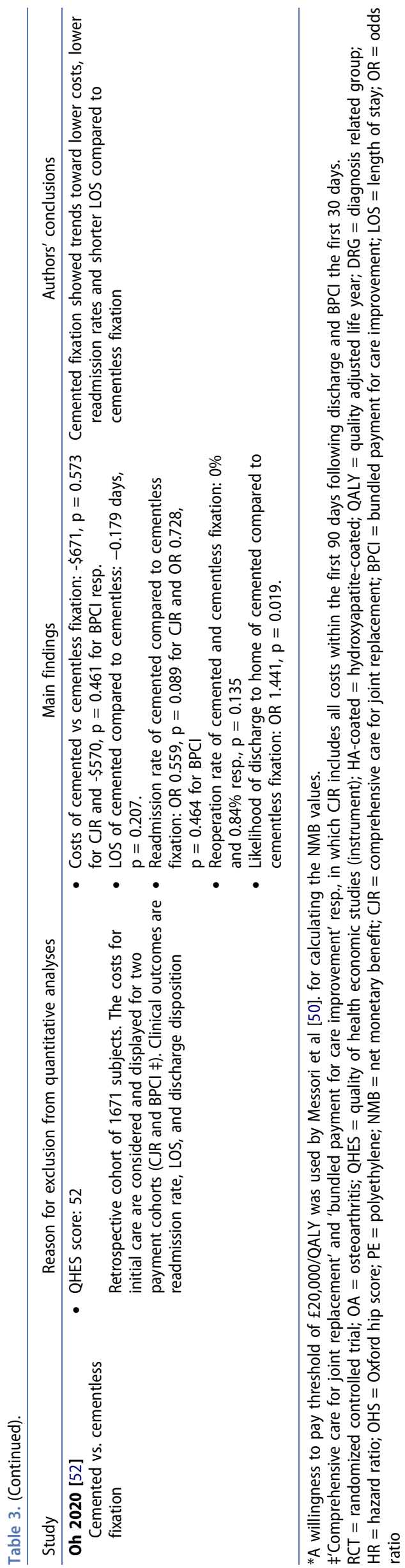

compared cementless and hybrid fixation [47], three studies only compared cemented and cementless fixation [40,46,52], seven studies compared cemented, cementless and hybrid fixation [42-45,48-50], and in one study the cemented, cementless, hybrid and reverse hybrid fixation were compared [51]. Furthermore, varying subgroup-analyses, outcomes and time horizons have been studied along the included studies. An overview of the investigated implants per included study and the justification provided by the authors for examining those specific implants was presented in supplementary Table 1.

Most identified economic evaluations used a Markov model (7/12) $[42,43,46-48,50,51]$, while one study was a trial-based economic evaluation [40], and four were based on a retrospectively studied cohort (Table 1 ) $[44,45,49,52]$. The $\mathrm{RCT}$ and one retrospective cohort study were based on single center patient data [40,45], the study of Oh et al. [52] was based on data from the Medicare network, which consisted of nine hospitals, Messori et al. [50] was mainly based on data from the previous economic evaluation conducted by Pennington and colleagues [43], and all other identified studies were mainly based on data derived from large arthroplasty registries $[42-44,46-49,51]$. The seven studies on data from the UK, including the two retrospective cohort studies, used the National Joint Registry (NJR) [42-44,48,49,51]. The NJR database consists data from England, Wales, Northern Ireland and the Isle of Man [24]. Fawsitt et al. derived data from the Swedish Hip Arthroplasty Register (SHAR) as an addition to NJR data for the long-term revision risks, since this registry contains a follow-up of primary THAs up to 25 years [51]. Finally, the two Italian studies derived the patient data from the Register of the Orthopaedic Prosthetic Implants (RIPO) [46,47], which contains data from the EmiliaRomagna region in Italy [53].

The applied cost-perspective was not explicitly stated in six studies $[43-45,49,50,52]$, and for the studies that reported the cost-perspective, a substantial heterogeneity was observed (Table 1). However, all individual studies clearly described the costs that were considered in their methodology. Assessment of the considered costs revealed that all included studies, except for the trial-based study [40], applied a provider or third party payer perspective.

\subsection{Methodological quality}

The methodological quality of the identified economic evaluations was assessed according to the 16 criteria of the QHES and resulted in an overall quality score per study (Table 2). Five Markov model-based studies scored $>90$ and thus had an excellent methodological quality $[42,43,47,48,51]$. The seven remaining articles are not considered to have high methodological quality based on the QHES score (i.e. $<75)[40,44-46,49,50,52]$. A short-term follow-up ( $<10$ years) and the lack of high methodological quality $(\mathrm{QHES}<75)$ were reasons for excluding these studies from quantitative analyses $[40,44-46,49,50,52]$. The seven excluded studies with the reasons for exclusion, their main findings, and the derived conclusions are presented in Table 3. 


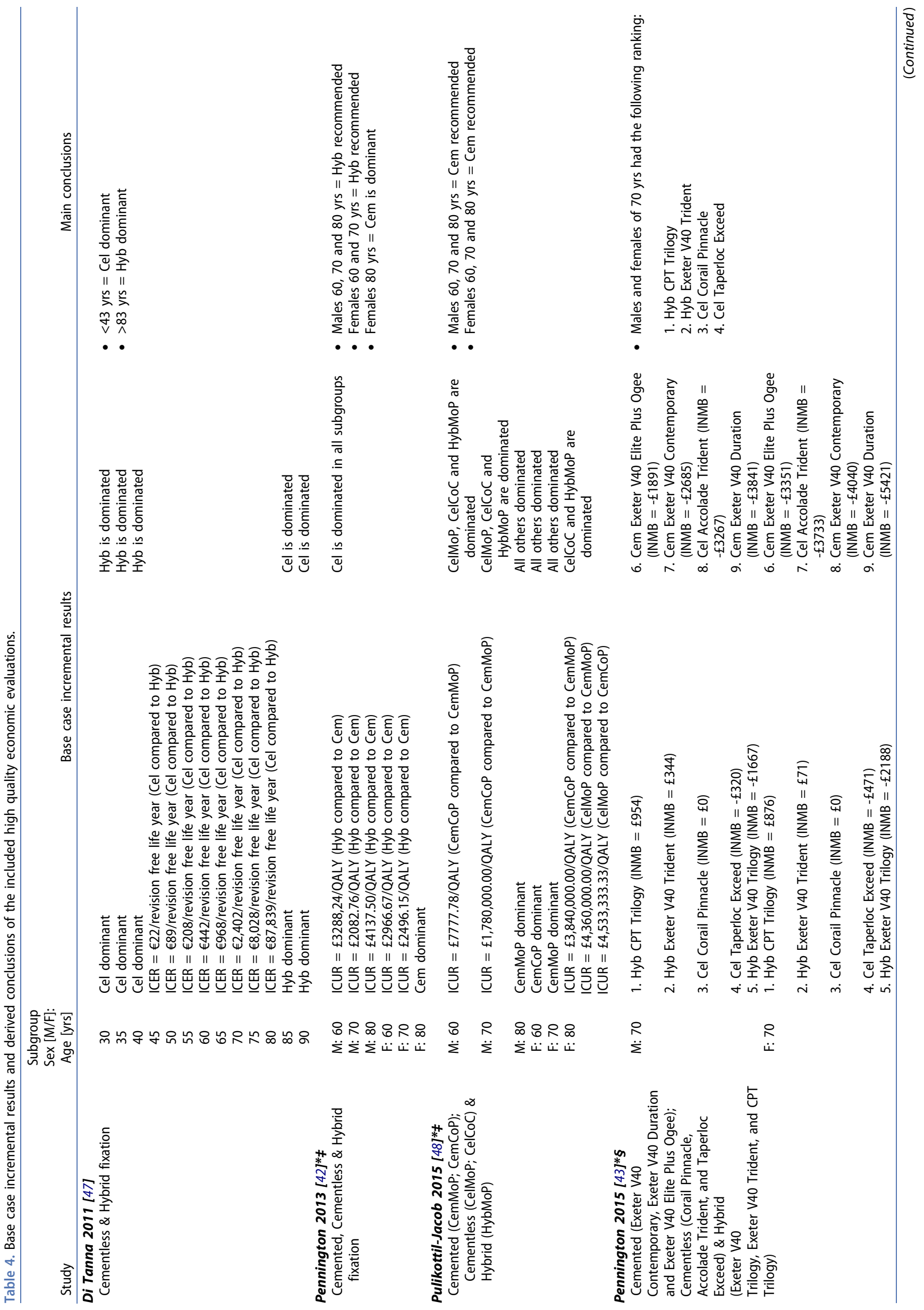




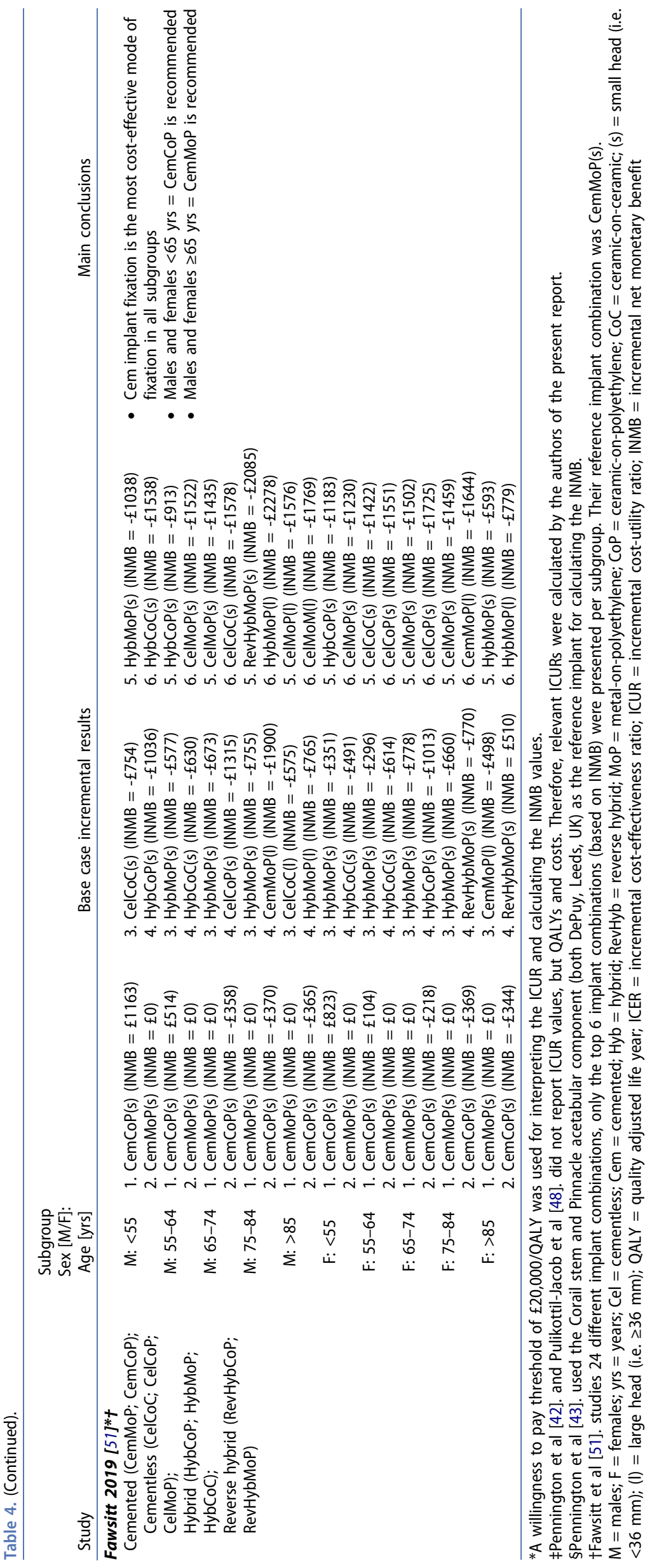




\subsection{High quality studies}

Five high quality studies were included in the analysis of results $[42,43,47,48,51]$. Four out of the five studies were performed in the UK and were based on data from the NJR $[42,43,48,51]$. These four studies all included cemented THAs in their investigation and observed that cemented fixation had the lowest lifetime costs in all studied groups [42,43,48,51]. QALYs were used to describe the outcome in these four studies [42,43,48,51], while Di Tanna et al. [47] examined revision-free life year as their endpoint. The latter study was conducted in Italy and was largely based on data from the RIPO database. The four studies that were conducted in the UK derived the QALYs from the National Patient Reported Outcome Measures (PROMs) programme [42,43,48,51]. Based on these 'baseline' QALYs, which are the input for their models, the lifetime QALYs were projected per implant combination of interest. Remarkably, two studies considered a single average QALY value per subpopulation at six months postoperatively for all implant combinations in their model $[48,51]$, while the other two used implant specific QALYs as input $[42,43]$.

\subsection{Base case incremental results of high-quality studies}

The base case incremental results and derived conclusions of the high-quality studies are presented in Table 4. Di Tanna et al. [47] compared cementless and hybrid fixation. Their base case incremental results were presented for 30 to 90-year olds in 5-year intervals. In patients aged 40 years or younger, cementless fixation was dominant, between 45 and 80 years of age the ICER increased from $€ 22$ to $€ 87,839$ per revision free life year. In patients aged 85 years or older, hybrid fixation was dominant. Pennington et al. [42] compared cemented, cementless and hybrid fixation, and stratified for age and sex. In males, hybrid fixation was cost-effective compared to cemented fixation in all age groups (ICUR ranged between $£ 2082.76$ and $£ 4137.50$ per QALY). In females aged 60 or 70 years, hybrid fixation was cost-effective compared to cemented fixation (ICURs were $£ 2966.67 / Q A L Y$ and $£ 2496.15$ / QALY respectively). Cemented fixation was, however, dominant in females of 80 years of age. Cementless fixation was dominated in all investigated ages for both sexes. PulikottilJacob et al. [48] compared cemented, cementless and hybrid fixation. In this study, patients were stratified based on age and sex, and the investigated implants were subdivided based on bearing surface. The cemented fixation mode was dominant for all investigated age groups and both sexes. Pennington et al. [43] compared cemented, cementless and hybrid fixation in males and females aged 70 years. They specifically investigated the three most commonly used implant combinations per fixation mode (supplementary Table 1). The Corail stem and Pinnacle acetabular component (both DePuy, Leeds, UK) were considered the reference implant combination because it was the most commonly implanted combination in their database. Subsequently, a ranking was made based on the INMB values. For males and females, the top three implants were: 1. CPT Trilogy [hybrid] (both Zimmer, Warsaw, Indiana) (INMB $=£ 954$ and $£ 876$ resp.), 2.Exeter V40 Trident [hybrid] (both Stryker, Newbury, UK) (INMB $=£ 344$ and $£ 71$ resp.), and 3. the Corail Pinnacle [cementless] (reference implant, INMB $=£ 0$ ). Fawsitt et al. [51] compared cemented, cementless, hybrid and reverse hybrid fixation in males and females in several age categories. The investigated implants were subdivided based on bearing surface and head size (small $<36 \mathrm{~mm}$ versus large $\geq 36 \mathrm{~mm}$ ). Therefore, they studied a total of 24 implant combinations. As a reference implant combination, the cemented metal-onpolyethylene implant with small head combination was chosen and a ranking list based on the INMB was constructed. Cemented fixation (with metal-on-polyethylene or ceramic-onpolyethylene bearing and a small head) obtained the first and second place in the ranking for all age categories and both sexes. The reference combination was first in the ranking list for males and females aged $>65$ years (INMB $=0$ ). In males and females aged $<55$ years, cemented implants with ceramicon-polyethylene bearing and a small head had the highest INMB values (INMB $=£ 1163$ and $£ 823$ resp.). This implant combination also had the highest INMB values in males and females of 55-64 years (INMB $=£ 514$ and $£ 104$ resp.).

The assessment of trends along the base case incremental results along studies revealed that no study described full cementless implant fixation to be the most cost-effective fixation mode for any of the investigated subgroups, except for very young populations described by Di Tanna et al. [47]. In this study, cementless fixation was dominant over hybrid fixation in patients aged $<43$ years. Two studies described cemented fixation as the most cost-effective in all studied age groups and both genders [48,51], and two studies stated hybrid fixation as the most cost-effective in most subpopulations $[42,43]$. All authors, including Di Tanna et al., recommended stem fixation with bone cement in the eldest populations for both sexes $[42,43,47,48,51]$.

\section{Discussion}

This systematic review identified 12 studies that compared costs and outcomes between different modes of implant fixation in THA. Analyses of results were performed on solely the five high quality CEAs $[42,43,47,48,51]$, which were mainly conducted in the UK and based on data from the NJR. In general, it was found that cemented fixation of the femoral component seems most cost-effective in THA for all relevant age groups and both sexes, while conflicting results were found on the most cost-effective mode of fixation of the acetabular cup. Except for Di Tanna et al. [47], who found that cementless fixation was cost-effective compared to hybrid fixation in a young Italian patient population, no other studies found cementless fixation to be the most cost-effective mode of fixation in THA for any of the studied subgroups.

In the interpretation of our results, some issues must be taken into account. Firstly, it seems that results of individual studies are largely dependent on assumptions in the methodology regarding QALY data. All studies that included QALYs derived their data from the PROMs database in the UK. The data is collected immediately before surgery and six months 
after primary or revision THA [54]. The increase in QALYs during this period was used for the projection of lifetime QALYs. However, two studies assumed that the initial increase in utility following surgery was equal for all components $[48,51]$, while the two other studies used the implant-specific utilities as input $[42,43]$. Interestingly, the studies that considered the implants as equal regarding utility at six months postoperative, found that cemented fixation was the most cost-effective mode of fixation in all subgroups [48,51]. The studies with the implant-specific input for QALYs however, concluded that hybrid fixation was the most cost-effective fixation mode in most subgroups $[42,43]$. A potential explanation for this phenomenon would be the higher utility of hybrid fixation in general [42], or for certain hybrid implants [43] at six months after surgery. Therefore, studies that considered this implant-specific utility, extrapolated these differences in the lifetime QALY calculation. Studies that considered the utility input as equal for different components, however, did not observe higher lifetime QALYs in alternative fixation modes that could compensate for the lower lifetime costs of cemented fixation. Therefore, these studies concluded that cemented fixation was the most cost-effective [48,51]. This phenomenon was also observed in the sensitivity analysis of one study [42]. If it was assumed that QALY differences only existed during the first two postoperative years, instead of a lifetime extrapolation, the probability that cemented fixation was most cost-effective instead of hybrid fixation increased [42]. It is a dubious assumption whether differences between implants at six months postoperatively remain unchanged for the rest of patients' life, especially since clinical improvements are known to occur after the initial six postoperative months [55]. However, further research is needed toward the postoperative course of utility and the potential existing differences between implants at longer follow-up.

Secondly, cautious interpretation of the results is recommended due to the uncertainty in the individual CEAs that were included. It was stated that differences in costeffectiveness between the top 4 implants were small in the study of Pennington et al. [43], that differences in QALYs and costs between categories were extremely small and borderline respectively in the study of Pulikottil-Jacob et al. [48], and that the probability that any implant was most cost-effective was much lower after harmonizing implant prices in the study of Fawsitt et al [51].

Thirdly, the main input sources of data of the included CEAs have to be considered. Data was mainly derived from large arthroplasty registries in general. The use of large arthroplasty registries is currently optimal for obtaining sufficient numbers of patients and adequate follow-up length in order to perform CEAs on implant optimization in THA. However, a drawback of arthroplasty registry data is their observational nature. As a consequence, a fair risk of selection bias exists. Although all included high quality studies performed risk adjustments based on known risk factors (e.g. sex, age, ASA class, BMI, revision-free interval etc.), the occurrence of selection bias cannot be ruled out completely $[42,43,47,48,51]$.

Fourthly, differences in the costs of treatment and public reimbursement systems between countries impact the results and complicate the generalizability and the transferability between countries. Accordingly, a study performed by Stargardt assessed variations in the costs of primary hip replacement between nine member states of the European Union (EU) and found considerable differences between and within countries [56]. It was found that treatment costs ranged between $€ 1290$ (Hungary) to $€ 8739$ (The Netherlands), with a mean cost of $€ 5043$ (SD $\pm € 2071$ ). Especially large differences in costs were found between Poland and Hungary, and the other studied EU member states (mean costs of primary THA per investigated country: Italy $=€ 6982$, Germany $=€ 6364$, France $=€ 6101$, Denmark $=€ 5932$, England $=€ 5691$, The Netherlands $=€ 5605$, Spain $=€ 3599$, Poland $=€ 2125$, Hungary $=€ 1294)$. In case input parameters between countries are not exactly aligned, the conclusions may still be comparable. However, in order draw solid conclusions for a specific healthcare system, a specific study within that health system is desirable because of the higher internal validation. Also differences in clinical practice between countries should be considered, since it was observed that incidence rates, patient characteristics, surgical technique, and implant trends in THA differ between countries [23]. Therefore, although we aimed to present an overview of all published results, our overall findings should be interpreted with caution, especially for healthcare systems other than the UK.

Finally, the timeliness of studies included in our review should be considered. In THA, new insights have emerged, and advances have been made over the last decades. Therefore, relatively old publications might potentially influence the outcomes of interest due to the use of discontinued component designs and suboptimal operative techniques or patient selection. Although this is relevant for the interpretation of individual studies in general, we do not believe that this was a major issue in the current review. All high methodological quality studies included in the current review were published between 2011 and $2019[42,43,47,48,51]$. Therefore, the 'oldest' publication with a high methodological quality was published $<10$ years ago. Furthermore, all high-quality studies were conducted in well developed countries (i.e. Italy and the UK). Accordingly, the implant combinations that were studied in the high-quality studies are considered currently relevant implants (supplementary Table 1) and patients underwent surgery mainly because of osteoarthritis of the hip. Information on surgical approach or procedural data was not provided in any of the high-quality studies. Since the studies were based on national databases, it is assumed that several surgical approaches have been included in their patient populations. Overall, it is our belief that the data of the high-quality included studies are representative for current practice. However, the timeliness of costs has to be considered as well. It was chosen to present and interpret the results of individual studies in this systematic review as they were published, as this ensures transparency and verifiability. Therefore, no reference year or a single reference currency was stated in the methodology. As a consequence, the willingness to pay was defined for multiple currencies. In our review, the year of valuation of the high-quality studies ranged between 2010 and 2016 (Table 1). All high quality studies that reported costs and utility, reported costs in sterling pounds $(£)[42,43,48,51]$. Two studies 
reported INMB-values by the use of a willingness to pay threshold of $£ 20,000$ /QALY, which was in accordance with the willingness to pay threshold of the current review [48,51]. The timeliness of costs is considered not to complicate the comparability between studies tremendously, since the range in years of valuation between studies is considered acceptable and the willingness to pay was solely applied as £20,000/QALY. However, one should always be aware of the timeliness of the exchange rate and valuation year of individual studies when interpreting economic evaluations.

The total number of available studies on this topic is currently limited $(n=12)$, especially those of high methodological quality $(n=5)$. The current review aimed to present all available evidence, no restrictions regarding country of origin were therefore stated. Accordingly, since four out of the five high quality studies were mainly based on NJR data, we conclude that it is currently too early for reviews on specific countries other than the UK. Comparable CEAs based on data from other national arthroplasty registries are much needed in order to overcome transferability problems to other countries. In future studies it would be interesting to incorporate a societal cost perspective as well. Koenig et al. performed a CEA with a societal perspective on THA in general and stated that THA averagely resulted in a net societal saving of USD 32,948 per patient and a gain of 5.5 QALYs when compared to nonsurgical treatment [57]. Especially in the younger populations, the postoperative gain in productivity may be associated with substantial benefits for society $[57,58]$. Potential differences in rehabilitation time or time of return to work therefore may be of societal interest.

To the best of our knowledge, this is the first systematic review that focuses on cost-effectiveness between the available modes of implant fixation in THA. Economic evaluations for objective healthcare evaluation and decision guidance are becoming increasingly important within the field of orthopaedic surgery [59-61]. Previous work on the cost-effectiveness of THA stated the procedure to be highly cost-effective, even in high risk populations and the eldest age groups [57,62-66]. Previously published reviews on cost-effectiveness in THA had a broader scope and more exploring nature than the present review $[62,66]$. These previous reviews identified only one [62] or two studies [66] that investigated the mode of fixation, which were also identified by our systematic search and subsequently considered methodologically inferior based on the QHES [45,46], which emphasizes the added value of the present review.

\section{Conclusion}

Currently available high-quality cost-effectiveness studies on the optimal implant fixation mode in THA suggest hybrid or cemented fixation to be the most cost-effective for most age groups and both genders. Cementless fixation as the main mode of fixation is therefore not supported by currently available CEAs. These findings are however uncertain and depend on assumptions in the methodology of individual studies. Furthermore, the number of available studies on this topic is limited and particularly based on a single national arthroplasty registry, which complicates the transferability of results to other healthcare systems. Future work is therefore much needed. Currently, cost-effectiveness studies should not be the only evidence to consider when choosing a certain implant fixation mode in clinical practice.

\section{Declaration of interest}

The authors have no relevant affiliations or financial involvement with any organization or entity with a financial interest in or financial conflict with the subject matter or materials discussed in the manuscript. This includes employment, consultancies, honoraria, stock ownership or options, expert testimony, grants or patents received or pending, or royalties.

\section{Reviewers disclosure}

Peer reviewers on this manuscript have no relevant financial relationships or otherwise to disclose.

\section{Author contributions}

H.D. Veldman: study idea, study design, literature search, literature selection, data extraction, quality assessment, interpretation and reflection, writing the manuscript

R.T.A.L. de Bot: study design, literature search, literature selection, data extraction, quality assessment, interpretation and reflection, reviewing the manuscript

I.C. Heyligers: study design, interpretation and reflection, reviewing the manuscript

T.A.E.J. Boymans: study design, interpretation and reflection, reviewing the manuscript

M. Hiligsmann: study design, literature selection, quality assessment, interpretation and reflection, reviewing the manuscript

\section{Funding}

This paper was not funded.

\section{ORCID}

H.D. Veldman (D) http://orcid.org/0000-0002-0579-7499 M. Hiligsmann (D) http://orcid.org/0000-0003-4274-9258

\section{References}

Papers of special note have been highlighted as either of interest $(\cdot)$ or of considerable interest $(\cdot \cdot)$ to readers.

1. Learmonth ID, Young C, Rorabeck $C$. The operation of the century: total hip replacement. Lancet. 2007;370(9597):1508-1519.

2. Pivec R, Johnson AJ, Mears SC, et al. Hip arthroplasty. Lancet. 2012;380(9855):1768-1777.

3. Pabinger $C$, Geissler $A$. Utilization rates of hip arthroplasty in $O E C D$ countries. Osteoarthritis Cartilage. 2014;22(6):734-741.

4. Kurtz S, Ong K, Lau E, et al. Projections of primary and revision hip and knee arthroplasty in the United States from 2005 to 2030. J Bone Joint Surg Am. 2007:89(4):780-785.

5. Singh JA. Epidemiology of Knee and Hip Arthroplasty: A Systematic review. The Open Orthopaedics Journal. 2011;5(1):80-85.

6. Culliford D, Maskell J, Judge A, et al. Future projections of total hip and knee arthroplasty in the UK: results from the UK Clinical Practice Research Datalink. Osteoarthritis Cartilage. 2015;23 (4):594-600.

7. Nemes S, Gordon M, Rogmark C, et al. Projections of total hip replacement in Sweden from 2013 to 2030. Acta orthopaedica. 2014;85(3):238-243.

8. Clarius $M$, Heisel C, Breusch SJ. Pulmonary embolism in cemented total hip arthroplasty. In: Breusch SJ, Malchau H, editors. The well 
cemented total hip arthroplasty. Berlin: Springer Medizin Verlag; 2005. p. 320-331.

9. Smabrekke A, Espehaug B, Havelin LI, et al. Operating time and survival of primary total hip replacementsAn analysis of 31745 primary cemented and uncemented total hip replacements from local hospitals reported to the Norwegian Arthroplasty Register 1987-2001. Acta Orthop Scand. 2004;75(5):524-532.

10. Veldman HD, Heyligers IC, Grimm B, et al. Cemented versus cementless hemiarthroplasty for a displaced fracture of the femoral neck. The Bone \& Joint Journal. 2017;99-B(4):421-431.

11. Ayre WN, Denyer SP, Evans SL. Ageing and moisture uptake in polymethyl methacrylate (PMMA) bone cements. Journal of the Mechanical Behavior of Biomedical Materials. 2014;32:76-88.

12. Troelsen A, Malchau $E$, Sillesen $N$, et al. A review of current fixation use and registry outcomes in total hip arthroplasty: the uncemented paradox. Clin Orthop Relat Res. 2013;471 (7):2052-2059.

13. Moskal JT, Capps SG, Scanelli JA. Still no single gold standard for using cementless femoral stems routinely in total hip arthroplasty. Arthroplasty Today. 2016;2(4):211-218.

14. Phedy P, Ismail HD, Hoo C, et al. Total hip replacement: A meta-analysis to evaluate survival of cemented, cementless and hybrid implants. World Journal of Orthopedics. 2017;8(2):192-207.

15. Abdulkarim A, Ellanti P, Motterlini N, et al. Cemented versus uncemented fixation in total hip replacement: a systematic review and meta-analysis of randomized controlled trials. Orthopedic Reviews. 2013;5(1):e8.

16. Lopez-Lopez JA, Humphriss RL, Beswick AD, et al. Choice of implant combinations in total hip replacement: systematic review and network meta-analysis. BMJ. 2017;359:j4651.

- A systematic review and network meta-analysis investigating the clinical success of different implant combinations in total hip arthroplasty.

17. Makela KT, Matilainen M, Pulkkinen $P$, et al. Failure rate of cemented and uncemented total hip replacements: register study of combined Nordic database of four nations. BMJ. 2014;348(jan13 12):f7592. .

18. Lehil MS, Bozic KJ. Trends in total hip arthroplasty implant utilization in the United States. J Arthroplasty. 2014;29(10):1915-1918.

19.. No Authors listed. Register of orthopedic prosthetic implantology. Laboratorio di Tecnologia Medica I.O.R.: overall Data Hip and Knee Arthroplasty. 2005.

20. Lucht LU. The danish hip arthroplasty register. Acta Orthop Scand. 2000;71(5):433-439.

21.. No authors listed. Dutch Arthroplasty Register (LROI): annual report 2018.

22.. No authors listed.National Joint Replacement Registry, Australian Orthopaedic Association (AOA): annual report 2018.

23. Paxton EW, Cafri G, Nemes S, et al., An international comparison of THA patients, implants, techniques, and survivorship in Sweden, Australia, and the United States. Acta Orthopaedica. 90(2): 148-152. 2019.

- Interesting study on international differences in current total hip arthroplasty practice regarding patients, implants, techniques, and survivorship.

24.. No authors listed. National Joint Registry for England and Wales: 14th Annual report, 2018.

25.. No Authors Listed. Norwegian National Advisory Unit on Arthroplasty and Hip Fractures. Annual report 2019.

26.. No Authors Listed. Swedish Hip Arthroplasty Register.Annual report 2017.

27. Unnanuntana A, Dimitroulias A, Bolognesi MP, et al. Cementless Femoral Prostheses cost more to implant than cemented Femoral Prostheses. Clinical Orthopaedics and Related Research ${ }^{\circledR}$. 2009;467 (6):1546-1551.

28. Griffiths EJ, Stevenson D, Porteous MJ. Cost savings of using a cemented total hip replacement. The Journal of Bone and Joint Surgery. British Volume. 2012;94-B(8):1032-1035.

29. Moher D, Liberati A, Tetzlaff J, et al. Preferred reporting items for systematic reviews and meta-analyses: the PRISMA statement. BMJ. 2009;339(jul21 1):b2535.
30. Drummond M, Sculpher MJ, Torrance GW, et al. Methods for the economic evaluation of health care programmes. 3rd ed ed. Oxford; New York: Oxford University Press; 2005.

- Exhaustive and detailed book on techniques and tools for economic evaluations of health care programmes.

31. Ofman JJ, Sullivan SD, Neumann PJ, et al. Examining the value and quality of health economic analyses: implications of utilizing the QHES. J Manag Care Pharm. 2003;9(1):53-61. .

32. Chiou C-F, Hay JW, Wallace JF, et al. Development and validation of a grading system for the quality of cost-effectiveness studies. Med Care. 2003;41(1):32-44.

33. Spiegel BMR, Targownik LE, Kanwal F, et al. The quality of published health economic analyses in digestive diseases: a systematic review and quantitative appraisal. Gastroenterology. 2004;127 (2):403-411.

34. Evans JT, Evans JP, Walker RW, et al. How long does a hip replacement last? A systematic review and meta-analysis of case series and national registry reports with more than 15 years of follow-up. Lancet. 2019;393(10172):647-654. .

- An interesting systematic review with meta-analysis that estimates: 'how long does a total hip replacement last?'

35. Pratt JW, Zeckhauser RJ. Willingness to pay and the distribution of risk and wealth. J Polit Econ. 1996;104(4):747-763.

36. Owens DK. Interpretation of cost-effectiveness analyses. J Gen Intern Med. 1998;13(10):716-717.

37. McCabe C, Claxton K, Culyer AJ. The NICE cost-effectiveness threshold: what it is and what that means. Pharmacoeconomics. 2008;26 (9):733-744.

38.. No authors listed. Ziektelast in de praktijk. De theorie en praktijk van het berekenen van ziektelast bij pakketbeoordelingen. Zorginstituut Nederland. 2018.

39. Laupacis A, Bourne R, Rorabeck C, et al. Costs of elective total hip arthroplasty during the first year. The Journal of Arthroplasty. 1994;9 (5):481-487.

40. Rorabeck CH, Bourne RB, Laupacis A, et al. A double-blind study of 250 cases comparing cemented with cementless total hip arthroplasty. Cost-effectiveness and its impact on health-related quality of life. Clinical Orthopaedics and Related Research. 1994;298:156-164.

41. Bourne RB, Rorabeck $\mathrm{CH}$, Laupacis $\mathrm{A}$, et al. A randomized clinical trial comparing cemented to cementless total hip replacement in 250 osteoarthritic patients: the impact on health related quality of life and cost effectiveness. The lowa Orthopaedic Journal. 1994;14:108-114.

42. Pennington $M$, Grieve $R$, Sekhon JS, et al. van der Meulen JH. Cemented, cementless, and hybrid prostheses for total hip replacement: cost effectiveness analysis. BMJ. 2013;346(feb27 1):f1026. .

- A good economic evaluation assessing the cost effectiveness of cemented, cementless and hybrid fixation of components in total hip arthroplasty.

43. Pennington MW, Grieve R, van der Meulen JH. Lifetime cost effectiveness of different brands of prosthesis used for total hip arthroplasty: a study using the NJR dataset. The Bone \& Joint Journal. 2015;97-B(6):762-770. .

- A good economic evaluation assessing the cost effectiveness of nine commonly used specific implants in total hip arthroplasty.

44. Jameson SS, Mason J, Baker $P$, et al. Have cementless and resurfacing components improved the medium-term results of hip replacement for patients under 60 years of age? Acta Orthop. 2015;86(1):7-17.

45. Givon U, Ginsberg GM, Horoszowski $\mathrm{H}$, et al. Cost-utility analysis of total Hip Arthroplasties: technology assessment of surgical procedures by mailed questionnaires. International Journal of Technology Assessment in Health Care. 1998;14(4):735-742.

46. Marinelli $M$, Soccetti A, Panfoli $N$, et al. Cost-effectiveness of cemented versus cementless total hip arthroplasty. A Markov Decision Analysis Based on Implant Cost J Orthop Traumatol. 2008;9(1):23-28.

47. Di Tanna GL, Ferro S, Cipriani F, et al., Modeling the cost-effectiveness for cement-less and hybrid prosthesis in total 
hip replacement in Emilia Romagna, Italy. J Surg Res. 169(2): 227-233. 2011.

- A good economic evaluation assessing the cost-effectiveness of cementless versus hybrid total hip arthroplasty.

48. Pulikottil-Jacob R, Connock M, Kandala N-B, et al., Cost effectiveness of total hip arthroplasty in osteoarthritis: comparison of devices with differing bearing surfaces and modes of fixation. The Bone \& Joint Journal. 97B(4): 449-457. 2015.

- A good economic evaluation assessing five different implant combinations in total hip arthroplasty regarding implant fixation mode and bearing surface.

49. Jameson SS, Mason J, Baker PN, et al. Implant optimisation for primary Hip replacement in patients over 60 years with Osteoarthritis: a cohort study of clinical outcomes and implant costs using data from England and Wales. PLoS One. 2015;10(11):e0140309.

50. Messori A, Trippoli S, Marinai C. Handling the procurement of prostheses for total hip replacement: description of an original value based approach and application to a real-life dataset reported in the UK. BMJ Open. 2017;7(12):e018603.

51. Fawsitt CG, Thom HHZ, Hunt LP, et al., Choice of Prosthetic Implant Combinations in Total Hip Replacement: cost-Effectiveness Analysis Using UK and Swedish Hip Joint Registries Data. Value Health. 22 (3): 303-312. 2019.

- A good economic evaluation assessing the cost effectiveness of 24 implant combinations in total hip arthroplasty regarding implant fixation mode, bearing surface and head size.

52. Oh JH, Yang W, Moore T, et al. Does femoral component cementation affect costs or clinical outcomes after hip arthroplasty in medicare patients? J Arthroplasty. 2020;35(6):1489-1496.e4. epub ahead of print.0

53.. No authors listed.Report of R.I.P.O. Register of orthopedic prosthetic implantology. Laboratorio di Tecnologia Medica I.O.R.: overall Data Hip and Knee Arthroplasty. 2005.

54. No authors listed. Finalised Patient Reported Outcome Measures (PROMs) in England - data quality note april 2016 to march 2017. 2018. August 2018 release

55. Browne JP, Bastaki $\mathrm{H}$, Dawson J. What is the optimal time point to assess patient-reported recovery after hip and knee replacement? A systematic review and analysis of routinely reported outcome data from the English patient-reported outcome measures programme. Health Qual Life Out. 2013;11:128.
56. Stargardt T. Health service costs in Europe: cost and reimbursement of primary hip replacement in nine countries. Health Economics. 2008;17(S1):S9-20. .

- Interesting study that assesses variations in the cost of primary total hip replacement between and within nine member states of the European Union (EU).

57. Koenig L, Zhang Q, Austin MS, et al. Estimating the societal benefits of THA after accounting for work status and productivity: A Markov model approach. Clin Orthop Relat Res. 2016;474 (12):2645-2654.

58. Sankar A, Davis AM, Palaganas MP, et al. Return to work and workplace activity limitations following total hip or knee replacement. Osteoarthritis Cartilage. 2013;21(10):1485-1493.

59. Brauer CA, Neumann PJ, Rosen AB. Trends in cost effectiveness analyses in orthopaedic surgery. Clinical Orthopaedics \& Related Research. 2007;457:42-48.

60. Brauer $C A$, Rosen $A B$, Olchanski NV, et al. Cost-utility analyses in orthopaedic surgery. J Bone Joint Surg Am. 2005;87 (6):1253-1259.

61. Bozic KJ, Saleh KJ, Rosenberg AG, et al. Economic evaluation in total hip arthroplasty: analysis and review of the literature. J Arthroplasty. 2004;19(2):180-189.

62. Daigle ME, Weinstein AM, Katz JN, et al. The cost-effectiveness of total joint arthroplasty: a systematic review of published literature. Best Pract Res Clin Rheumatol. 2012;26(5):649-658.

63. Kunkel ST, Sabatino MJ, Kang R, et al. The Cost-Effectiveness of Total Hip Arthroplasty in Patients 80 Years of Age and Older. J Arthroplasty. 2018;33(5):1359-1367.

64. Lavernia CJ, lacobelli DA, Brooks L, et al. The Cost-Utility of Total Hip Arthroplasty: earlier Intervention, Improved Economics. J Arthroplasty. 2015;30(6):945-949.

65. Ponnusamy KE, Vasarhelyi EM, McCalden RW, et al. Costeffectiveness of total Hip Arthroplasty versus Nonoperative management in normal, overweight, obese, severely obese, morbidly obese, and super obese patients: A Markov model. J Arthroplasty. 2018;33(12):3629-3636.

66. Davies C, Shemilt I, Macgregor A, et al. Can choices between alternative Hip Prostheses be evidence based? A review of the economic evaluation literature. Rheumatology. 2009;48: 1106-17. 